events, arising from enhanced productivity, has been implicated in ocean anoxic events before $^{6,7}$, but not with a starting point of volcanically derived sulphate.

Adams and colleagues went a step further by creating a simple box model to reconstruct their sulphur isotope curve, assuming a prescribed increase in volcanically derived sulphate, and with a few basic assumptions regarding organic carbon production and pyrite burial. In addition to replicating their observations, they were able to estimate the maximum sulphate concentration of ambient seawater leading up to OAE2. Assuming a sevenfold increase in volcanism, the pre-OAE2 concentration could not exceed $1.4 \mathrm{mM}$, otherwise the effect of the additional volcanic sulphate supply would have had a negligible impact on microbial sulphate reduction. The modelling also helped them to describe the end of ocean anoxia: oxygen-free bottom waters and an increasing supply of organic material promoted the preservation of pyrite. Continued accumulation of this mineral would have reduced the sulphate available for microbes, eventually halting the enhanced nutrient supply to the surface.

Of course, the Western Interior Seaway may not be representative of global biogeochemical changes during OAE2. The seaway was a huge shallow-water sea connected to the Atlantic Ocean, with a large freshwater catchment ${ }^{8}$. As such, the amount of sulphate in this region was probably much lower than in the rest of the ocean. Taking into account that the Caribbean plateau volcanism took place 'next door' in geographical terms, there was certainly the potential for an environment that was unusually sensitive to sudden increases in sulphate concentration.

Nevertheless, the sensitivity of the location does not detract from the larger significance of the work. Low sulphate concentrations probably characterized the oceans $s^{9}$ during several periods in Earth's history; many of these periods also experienced episodes of massive volcanism. Consequently,
I anticipate a flurry of papers that will explore Adams and colleague's interesting conjecture $^{2}$, for OAE2 as well as for other anoxic events and stage boundaries.

Haydon P. Mort is in the Department of Geology, Federal University of Pernambuco, Cidade Universitária, 50.740-530, Recife - PE, Brazil. e-mail:h.mort@btinternet.com

References

1. Wortmann, U. G. \& Chernyavsky, B. M. Nature 446, 654-656 (2007).

2. Adams, D. C., Hurtgen, M. T. \& Sageman, B. B. Nature Geosci. 3, 201-204 (2010)

3. Turgeon, S. C. \& Creaser, R. A. Nature 454, 323-326 (2008).

4. Hansen, K. W. \& Wallmann, K. Am. J. Sci. 303, 94-148 (2003)

5. Canfield, D. E. Geochim. Cosmochim. Acta 65, 1117-1124 (2001)

6. Mort, H. P. et al. Geology 35, 483-486 (2007).

7. Boudreau, B. P. \& Westrich, J. T. Geochim. Cosmochim. Acta 48, 2503-2516 (1984)

8. Keller, G. et al. Palaeogeogr. Palaeoclimatol. Paleoecol. 211, 19-43 (2004).

9. Berner, R. A. Am. J. Sci. 304, 438-453 (2004)

10. Barclay, R. S., McElwain, J. C. \& Sageman, B. B. Nature Geosci. 3, 205-208 (2010)

\title{
HYDROLOGY
}

\section{Lake carbon}

Inland waters, such as lakes, reservoirs, wetlands and rivers, occupy only a small fraction of the Earths' surface, but have a disproportionate effect on the global carbon cycle. These land-based water bodies bury, cycle and emit significant sums of carbon. A large amount of the carbon taken up by terrestrial systems ends up in inland waters, where it can be buried in sediments, transported to the oceans, or mineralized and released back into the atmosphere as carbon dioxide.

Despite the climatic implications, little is known about the factors that regulate the balance between carbon burial and release in inland waters. Without this knowledge, it is difficult to determine the influence of climate change on lake carbon content, and ultimately carbon release.

Sarian Kosten, of Wageningen University, The Netherlands, and colleagues show that warm lakes contain more carbon dioxide than cool lakes (Glob. Biogeochem. Cycles doi:10.1029/2009GB003618; in the press). The researchers examined carbon dioxide concentrations in 82 shallow lakes in South America. The lakes spanned a large temperature gradient; annual mean temperature ranged from $4^{\circ} \mathrm{C}$ in the south, to $27^{\circ} \mathrm{C}$ in the north.

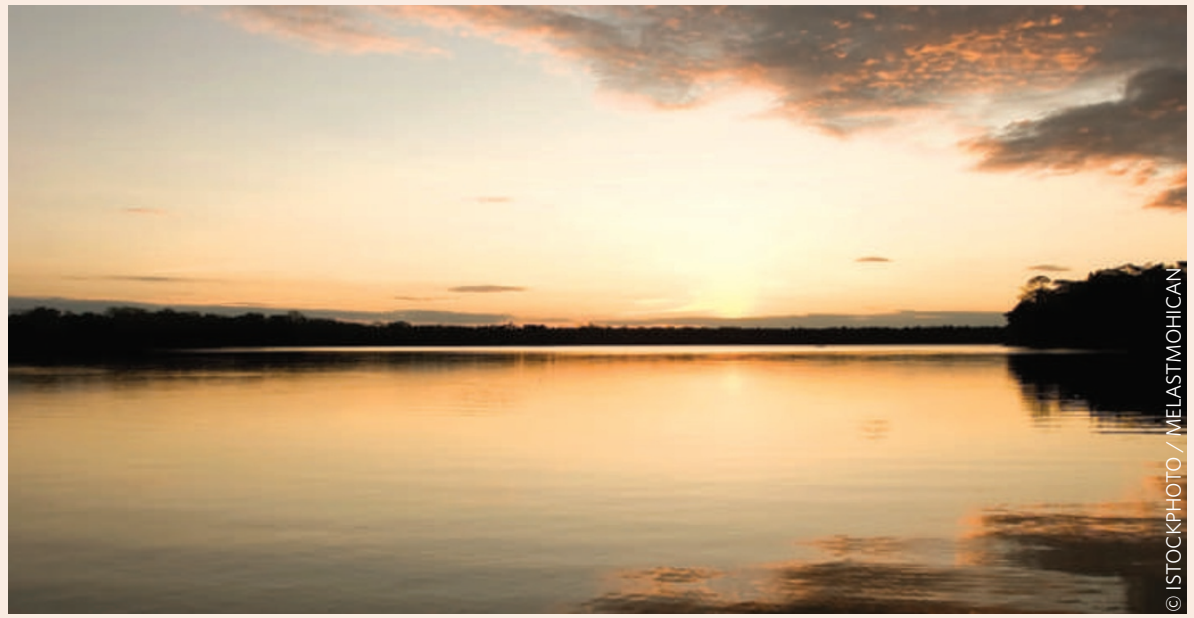

$80 \%$ of the lakes sampled contained higher concentrations of carbon dioxide than the atmosphere, indicating that they functioned as net sources of carbon dioxide. A regression analysis revealed that lake carbon dioxide concentrations increased with lake temperature. As expected, hydrology and primary productivity also explained a considerable part of the variance in lake carbon dioxide concentrations.

The authors suggest that the higher carbon dioxide concentrations in the warmer lakes can be explained by higher rates of respiration. Warm lakes might metabolize a greater proportion of the terrestrial organic carbon entering the water than cool lakes, leading to increased levels of carbon dioxide.

Because carbon dioxide concentrations in lakes have been found to be closely linked to carbon dioxide emissions from these water bodies, the researchers suggest that lakes in a warmer environment emit more of the greenhouse gas.

ANNA ARMSTRONG 